\title{
CASO-2017: Manejo de fístula aorto-cavitaria. Complicación de endocarditis bacteriana
}

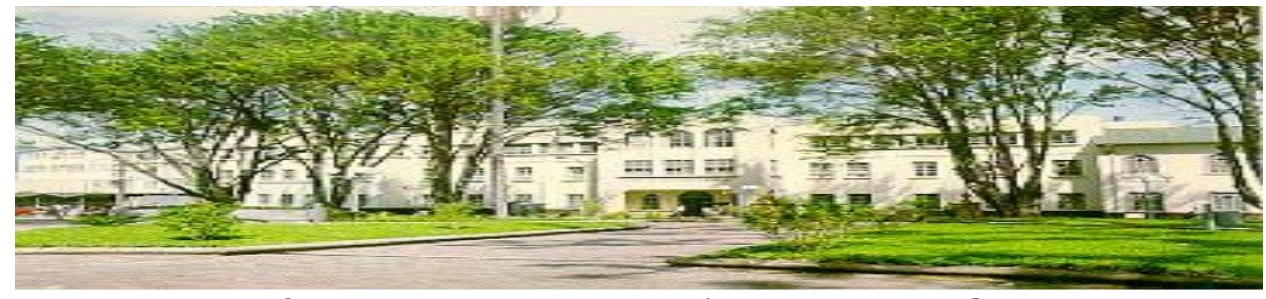

Haspital San quan de Dias, San Gosé, Casta Rica. Fundada en 1845

Recibido:

$10 / 05 / 2017$

Aceptado:

$15 / 06 / 2017$

Sofía Madrigal Jiménez $z^{1}$

Erick Sánchez Jiménez ${ }^{2}$

${ }^{1}$ Médico General. Correo electrónico: sofymadrigalj@gmail.com

${ }^{2}$ Residente de Cardiología. Hospital México. Correo electrónico: erick_fsj@hotmail.com

\section{RESUMEN}

Las fístulas son parte de las complicaciones de endocarditis bacteriana, las cuales tienen baja prevalencia según esta patología. Se presenta el caso de un paciente sin antecedentes personales patológicos conocidos que consultó por un cuadro de dos semanas de fiebre, asociado a mal estado general, en el cual se documentó según ecocardiograma una insuficiencia aórtica de novo, asociada a la presencia de una vegetación y una fístula en valva derecha, la cual fue tratada mediante reemplazo valvular aórtico mecánico, con adecuada evolución.

\section{PALABRAS CLAVE}

Endocarditis bacteriana. Fístula. Insuficiencia aórtica.
Fistulas are part of the complications of bacterial endocarditis, which have low prevalence according to this pathology. We present a case of a patient with unknown personal pathological history, who had two weeks of fever, associated with poor general condition. In an echocardiogram it is described an aortic insufficiency, associated with the presence of a vegetation and a fistula on the right valve, which is treated by mechanical aortic valve replacement, with adequate evolution.

\section{KEY WORDS}

Bacterial endocarditis. Fistula. Aortic insufficiency. 
Paciente masculino de 49 años de edad, sin antecedentes personales patológicos conocidos, quien se presentó al Servicio de Emergencias por un cuadro de dos semanas de evolución de fiebre, fatiga y astenia, por el cual consultó en varias ocasiones. Posteriormente asoció disnea de esfuerzo y ortopnea y se documentó soplo aórtico de insuficiencia, por lo que se refirió a un centro de primer nivel para completar estudios. Se reportó en el examen físico neurológico íntegro, febril, deshidratado, campos pulmonares con crépitos bibasales y ruidos cardíacos rítmicos con descripción de soplo diastólico de alto grado, plurifocal, de predominio aórtico, abdomen sin alteraciones y edemas en miembros inferiores. No se describieron lesiones en piel o en conjuntivas que se asocien a endocarditis.

Se realizó un electrocardiograma, que demostró ritmo sinusal regular con bloqueo de rama derecha del Haz de His y una radiografía de tórax que documentó cardiomegalia y datos de congestión pulmonar.

En los laboratorios se describió leucocitosis, PCR elevada (234 mg/L), pro-BNP 1169 pg/ml, lesión renal aguda pre-renal $\mathrm{y}$ troponina negativa. Un examen general de orina con hematuria y un urocultivo negativo. Debido a la asociación febril y clínica general del paciente, se realiza un hemocultivo es positivo por Streptococcus gallolyticus.

De acuerdo a la clínica y datos sugestivos de endocarditis, se decidió realizar un ecocardiograma transtorácico que documentó una insuficiencia aórtica severa tipo 2 de Carpentier, una vegetación de $16 \times 13 \mathrm{~mm}$ en la valva aórtica derecha que asoció prolapso de la misma de más de $10 \mathrm{~mm}$.

Al día siguiente se realizó manejo quirúrgico con reemplazo valvular aórtico mecánico, cierre de la fístula con puntos de sutura y además se documentó pericarditis fibrosa no purulenta, por lo que fue necesario la liberación de adherencias pericárdicas.

Durante el postoperatorio cursó cinco días con ventilación mecánica y una neumonía por Serratia marcescens sin alteración del estado hemodinámico. Recibió cobertura con penicilina intravenosa por seis semanas.

\section{DISCUSIÓN Y ANÁLISIS DEL CASO}

La extensión peri-valvular está presente en un rango de $10-30 \%$ de todas las endocarditis infecciosas de la válvula nativa. ${ }^{1}$ Dentro de estas se encuentran los abscesos, los pseudoaneurismas y las fístulas. ${ }^{2} \mathrm{La}$ incidencia de las fístulas ha sido difícil de establecer. En un estudio de 76 casos de fístulas aorto-cavitarias se documentó una prevalencia de $1.8 \%$ en válvulas nativas aórticas y un 3.5\% en válvulas protésicas aórticas. Se presentó con la misma frecuencia en los tres senos de Valsalva y comunicación con las cuatro cavidades cardíacas.,

Las fístulas se identifican con una media de 25 días posterior a la aparición de la sintomatología inicial y usualmente dentro de los primeros 5 días de la hospitalización. Más del $60 \%$ de los pacientes se presentan con falla cardíaca. ${ }^{3,4} \mathrm{La}$ mortalidad intrahospitalaria en algunos reportes es del $41 \%$, incluyendo tanto pacientes de manejo médico como quirúrgico. ${ }^{4}$

En estudios donde se le ha brindado manejo médico a pacientes con fístulas aorto-cavitarias, la mortalidad fue del $30 \%$, sin embargo se debe tomar en cuenta que estos pacientes son los que se presentaban con menos falla cardíaca. Aún así estos últimos pacientes tienen alta probabilidad de presentar complicaciones durante el primer y segundo año de seguimiento de al menos $40 \mathrm{y}$ $80 \%{ }^{4}$

Se documentaron en algunos casos complicaciones tales como bloqueos atrioventriculares completos e incompletos asociados a pacientes con fístulas por endocarditis. $^{5,6}$

Al parecer un aproximado de un $50 \%$ de las fístulas aorto-cavitarias son causadas por Staphylococcus aureus. ${ }^{7}$ El grupo viridans del estreptococo es bien conocido como causante de endocarditis, en el cual se encuentran organismos tales como el Streptococcus bovis o también llamado gallolyticus. Este agente está asociado con vegetaciones de mayor tamaño, pero no hay una frecuencia en la literatura con respecto a 
fístulas aorto-cavitarias. Es además una bacteria muy sensible al tratamiento con penicilina. ${ }^{8}$

Las guías Europeas de Cardiología describen que con respecto a la valoración de la endocarditis el ecocardiograma transtorácico tiene una sensibilidad del $50 \%$ en detectar abscesos comparado con una sensibilidad del $90 \%$ por ecocardiograma transesofágico, y una especificidad de $90 \%$ para ambos métodos diagnósticos. A pesar de esta información no se describe la capacidad de detección con respecto a fístulas. ${ }^{2}$ En el estudio danés, publicado en 1995, de 118 pacientes con endocarditis, se detectó por ecocardiograma transtorácico solo $25 \%$ de las cavidades perivalvulares con respecto a un $90 \%$ por ecocardiograma transesofágico. ${ }^{9}$ En un estudio más reciente, las complicaciones perivalvulares fueron detectadas por el eco transtorácico con una sensibilidad del $61 \%$ y por eco tranesofágico con una sensibilidad del $96 \%$, lo cual podría deberse a una mejoría en la técnica y el avance tecnológico. ${ }^{10}$

Las últimas guías de la Sociedad Europea de Cardiología del 2015 recomiendan que el manejo de los pacientes con fístulas por endocarditis asociadas a falla cardíaca sea mediante cirugía de emergencia. Además recomiendan cirugía urgente a los pacientes con fístulas sin asociar falla cardiaca. ${ }^{7}$

Por último, el pronóstico de los pacientes con endocarditis que asocian una complicación perivalvular es pobre. Las fístulas aortocavitarias están asociadas en mayor razón a falla cardíaca y complicaciones de conducción eléctrica como bloqueos atrio-ventriculares; sin embargo hay poca evidencia si esto las convierte en un factor de riego independiente de mortalidad. ${ }^{1,3,5}$

\section{CONCLUSIONES}

Las complicaciones de endocarditis infecciosa van desde abscesos y pseudoaneurismas, hasta fístulas aorto-cavitarias, las cuales tienen una incidencia baja. Es importante siempre realizar un ecocardiograma transesofágico en pacientes que se documenta endocarditis por un ecocardiograma transtorácico en busca de complicaciones que puedan modificar la decisión de manejo quirúrgico de urgencia versus emergencia. Cuando este shunt intracardíaco se presenta, causa mayor inestabilidad hemodinámica y mayor morbi-mortalidad, por lo que a pesar de ser una complicación poco frecuente se debe tomar en cuenta al valorar un paciente con endocarditis.

\section{BIBLIOGRAFÍA}

1. Grauper C Villacosta I SanRomán J, et al. Periannular extension of infective endocarditis. JACC. 2002; 39: 1212-1222.

2. Gilbert $\mathrm{H}$ LuigiB Cristophe $\mathrm{T}$, et al. Recomendations for the practice of echocardiography in infective endocarditis. Eur J Echocardiogr. 2010; 11: 202-219.

3. Angular I Miro JM Villacosta I, et al. Aortocavitary fistolous tract formation in infective endocarditis: clinical and echocardiographic features of 76 cases and risk factors for mortality. Eur Heart J. 2005; 26: 288-297.

4. Jenkink NP Habib G Prendergast BD. Aortocavitary fistulae in infective endocarditis: understanding a rare complication through collaboration. Eur Heart J. 2005; 26: 213.

5. Gales JN Perez IE Villablanca PA, et al. Aortocavitary fistula as a complication of infective endocarditis and subsequent complete heart block in a patient with anemia. J Community Hosp Intern Med Perspect. 2015; 6: 29446.

6. Kawahira $\mathrm{T}$ Iwahashi $\mathrm{K}$ Okada $\mathrm{M}$. Aortocavitary fistula without aneurysm and transient incomplete atrioventricular block due to infective endocarditis. Gen Thorac Cardiovasc Surg. 2010; 58: 45-48.

7. Habib G Lancelllotti P Antunes MJ, et al. 2015 ESC Guidelines dor the managment of infective endocarditis of the European Society of Cardiology. Eur Heart J. 2015; 36: 3075. 
8. Satué-Bartolome JA Sáenz M. Streptococcus gallolyticus: un nuevo nombre para un viejo conocido. Archivos de medicina. 2009; 5: 150.

9. Tingleff $\mathrm{J}$ Egeblad $\mathrm{H}$ Gotzsche $\mathrm{CO}$, et al. Perivalvular cavities in endocarditis: Abscesses versus pseudoaneurysm? A transesophageal doppler echocardiographic study in 118 patients with endocarditis. Am Heart J. 1995; 130: 93-100.

10. Anguera I Miro JM Evangelista A, et al. Perianular complications in infective endocarditis involving native aortic valves. Am J Cardiol. 2006; 98: 1254-1260.

\section{CONFLICTO DE INTERÉS Y/O AGRADECIMIENTOS}

Los autores declaran que no existió ningún conflicto de interés en el presente reporte. 
ANEXOS

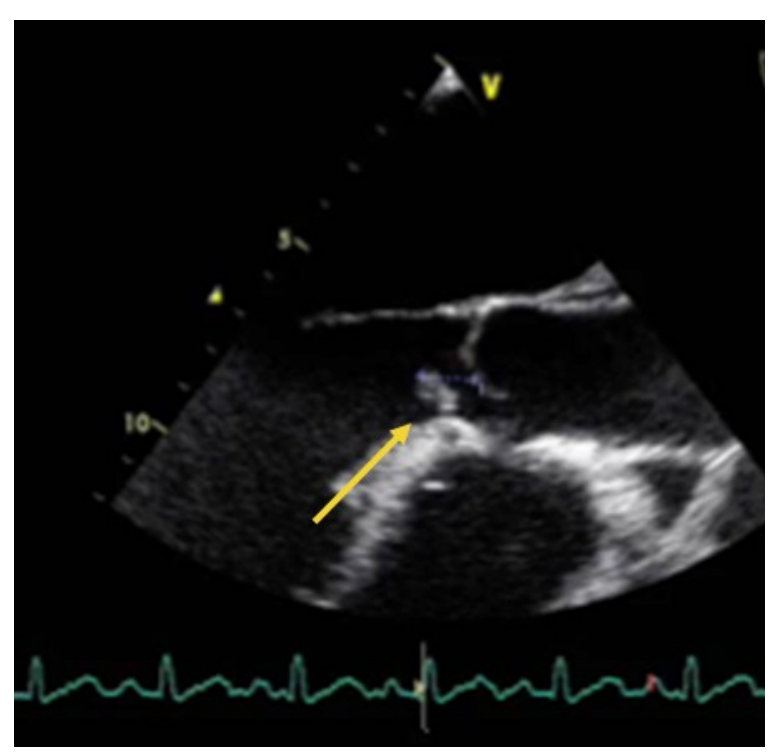

Figura 1. Prolapso de la válva aórtica derecha.

Fuente: Cardiología, Hospital México

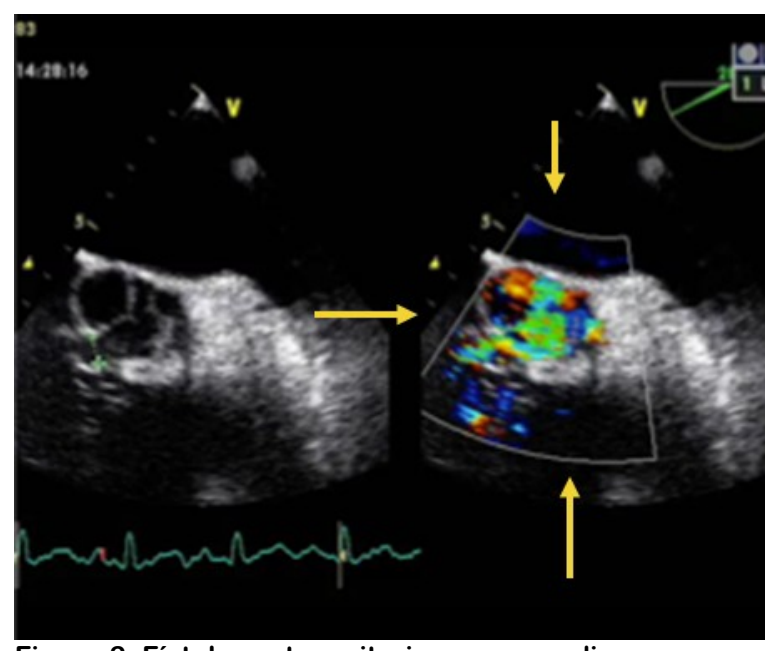

Figura 2. Fístula aortocavitaria en ecocardiograma transesofágico.

Fuente: Cardiología, Hospital México. 